\title{
Anemia in chronic heart failure patients: comparison between invasive and non-invasive prognostic markers
}

\section{Anemia nello scompenso cardiaco cronico: confronto tra indicatori prognostici invasivi e non invasivi}

\author{
Monica Ceresa, Soccorso Capomolla, GianDomenico Pinna, Eleonora Aiolfi, \\ Maria Teresa La Rovere, Oreste Febo, Vincenzo Paganini, Angelo Rossi, \\ Giampaolo Guazzotti, Angelo Caporotondi, Roberto Maestri, Franco Cobelli
}

\begin{abstract}
Anemia in chronic heart failure patients: comparison between invasive and non-invasive prognostic markers. M. Ceresa, S. Capomolla, G.D. Pinna, E. Aiolfi, M.T. La Rovere, O. Febo, V. Paganini, A. Rossi, G. Guazzotti, A. Caporotondi, R. Maestri, F. Cobelli.

Background: The prognosis of chronic heart failure (CHF) remains poor despite advances in medical management. Several different variables determine prognosis. Recently anemia has emerged as an independent prognostic variable in the evaluation of CHF. It is therefore important to analyze the role of anemia in patients with mild to severe CHF already well characterized by hemodynamic, echoDoppler, and cardiopulmonary exercise testing.

Objective: We performed this study to evaluate, in a large general cohort of CHF patients, the frequency of anemia and its correlation with their clinical profile. We assessed the prognostic value of anemia in relation to other known prognostic variables.

Methods: Two-dimensional echocardiography, right heart catheterization, cardiopulmonary tests and laboratory examinations were performed in a population of 980 consecutive patients with CHF (53 \pm 9.4 years, $85 \%$ male, LVEF $25 \pm 8 \%$; $45 \%$ with NYHA class III-IV). A hemoglobin (Hb) concentration less than $12 \mathrm{~g} / \mathrm{dl}$ was used to define anemic patients. The primary end point was cardiac death or urgent heart transplantation.
\end{abstract}

Results: Nineteen percent of patients were anemic. These patients had a lower body mass index $(24 \pm 3$ vs. $25 \pm 4$
$\left.\mathrm{Kg} / \mathrm{m}^{2} \mathrm{p}<0.0004\right)$, a worse functional class $(64 \%$ were in NYHA class III-IV vs $41 \%$ in the non-anemic group, p $<0.0001)$, poorer exercise capacity (12.4 vs. $14.8 \mathrm{ml} / \mathrm{kg} / \mathrm{min}$ peak $\left.\mathrm{VO}_{2}, \mathrm{p}<0.0001\right)$ and increased right $(7 \pm 5$ vs. $5 \pm 4$ $\mathrm{mmHg}, \mathrm{p}<.0004)$ and left $(21 \pm 9$ vs. $19 \pm 10 \mathrm{p}<0.007)$ ventricular filling pressures. During a 3-year follow-up cardiac deaths occurred in $236(24 \%)$ and $52(5 \%)$ of patients received an urgent heart transplant. On univariate regression analysis anemia was significantly correlated with these "hard" cardiac events (39\% of anemic patients vs $27 \%$ of non-anemic patients). By multivariate logistic regression analysis different prognostic models were identified using non-invasive, with or without peak $\mathrm{VO}_{2}$, or invasive parameters. The prognostic model including anemia $\left(A U C_{R O C}\right.$ : 0.720) showed similar accuracy in predicting cardiac events to other prognostic models with peak $\mathrm{VO}_{2}\left(\mathrm{AUC}_{\mathrm{ROC}}: 0.719\right)$ or invasive variables $\left(\mathrm{AUC}_{\mathrm{ROC}}: \mathbf{0 . 7 1 9}\right)$.

Conclusions: The present study demonstrates that anemia in CHF patients is associated with prognosis, worse NYHA functional class, exercise capacity and hemodynamic profiles. The relationship between anemia and mortality is independent of other simple non-invasive prognostic factors. Prognostic models with more complex or invasive independent predictors did not increase the accuracy to predict cardiac mortality or the need for urgent transplantation.

Keywords: anemia, chronic heart failure, prognosis.

Monaldi Arch Chest Dis 2005; 64: 124-133.

IRCCS Fondazione Salvatore Maugeri, Istituto Scientifico di Montescano (PV), Italia.

Financial support: This study had financial support by Ministero della Salute - Ricerca finalizzata N ICS 030.4/RF99.102.

Corresponding author: Soccorso Capomolla, Dept. of Cardiology, Montescano Medical Center. Via per Montescano - I-27040 Montescano - Pavia, Italy; E-mail address: scapomolla@fsm.it

The prognosis of chronic heart failure (CHF) remains poor despite advances in medical management, and mortality has been rising despite the improvements in medical and surgical therapy. ${ }^{1}$

Many factors are reported in the literature to predict prognosis, but their wide variety emphasises the fact that the prognostic accuracy of these factors still lacks consistency. Moreover, the clinical application of proposed prognostic models is limited because the characteristics of the derivation and application to patient-populations are different, or because the prognostic power of the variables has not been compared with those of consolidated variables. ${ }^{2}$ In recent years anemia has emerged as another prognostic variable for CHF.3-5 We therefore performed this study to evaluate, in a large general population of patients with CHF, the frequency of anemia and its correlation with the clinical profile. Furthermore, we assessed the prognostic value of anemia in conjunction with other established non-invasive and invasive prognostic variables. 


\section{Methods}

\section{Study population}

We evaluated 980 consecutive patients with CHF caused by ischemia, idiopathic dilated cardiomyopathy, or other disease (i.e. hypertension, valvular disease) admitted to the Heart Failure Unit of Montescano Medical Center for evaluation and treatment of advanced heart failure. All patients, in stable condition and receiving optimized therapy, had a functional evaluation by two-dimensional echocardiography, right heart catheterization, cardiopulmonary tests and laboratory examinations.

\section{Clinical evaluation}

We evaluated symptomatic severity by New York Heart Association (NYHA) classification. The clinical examination included assessment of body weight, body mass index (BMI), heart rate, third heart sound, and presence of peripheral or pulmonary edema (rales and/or orthopnea and turgor and/or hepato-jugular reflux).

The presence of other risk factors for CHF, such as increased age, male gender, family history of coronary artery disease, hypertension, smoking and diabetes mellitus were entered into the regression models.

\section{Laboratory testing}

Biochemical (serum concentrations of sodium, potassium, urea, creatinine, aspartate transaminase, glutamate transaminase, and bilirubin) and hematologic parameters (hemoglobin concentration, white cell and platelet counts) were measured. A hemoglobin concentration lower than $12 \mathrm{~g} / \mathrm{dl}$ was used to identify anemic patients.

\section{Cardiac catheterization}

Right heart catheterization was performed using a 7 F Swan-Ganz balloon-tipped catheter inserted into the right internal jugular vein and advanced to the pulmonary artery. Measurements were obtained with the patients in a supine position, using a HP transducer connected to a 7005 Marquette polygraph.

Pressure tracings were recorded at a speed of 50 $\mathrm{cm} / \mathrm{sec}$ on a scale calibrated from 0 to $60 \mathrm{mmHg}$.

Cardiac output was determined by averaging three consecutive thermodilution curves obtained by injecting $10 \mathrm{ml}$ of saline solution at $0^{\circ} \mathrm{C}$ into the right atrium.

Right atrial pressure, pulmonary artery pressures and mean pulmonary wedge pressure were recorded. The pulmonary capillary wedge position was confirmed by the appearance of a typical wedge pressure tracing during fluoroscopic observation of the catheter tip during balloon inflation.

Arterial systolic and diastolic blood pressures were measured with a non-invasive method by a calibrated v-lok-cuff connected to a 7005 Marquette system.

Heart rate was monitored continuously from a standard ECG.

\section{Echocardiography}

Echocardiographic studies were performed using an HP Sonos 1000 ultrasound system with 2.5 and $3.5 \mathrm{MHz}$ transducers.

We evaluated the diastolic and systolic left ventricular diameters from a parasternal long axis view and calculated left ventricular ejection fraction using a B-mode four-chamber view. ${ }^{6}$ The mitral regurgitation jet was evaluated as the ratio between jet area and left atrial area; regurgitation was ranked as mild, moderate or severe. ${ }^{7}$ In our analysis we considered moderate or severe mitral regurgitation in contrast to mild or no mitral regurgitation.

\section{Cardiopulmonary test}

Cardiopulmonary testing was performed in the upright position on an electronic bicycle. The cardiopulmonary parameters were measured breath by breath with an Oxycon Delta (Seager ${ }^{\mathrm{TM}}$ Medical technology) which was calibrated before each test. The following parameters were calculated: basal and peak $\mathrm{VO}_{2}$ in $\mathrm{ml} / \mathrm{min} / \mathrm{kg}$ of body weight.

\section{End points}

In this study the outcome event was cardiac death or urgent heart transplant. Cardiac deaths were those due to heart failure or sudden death; transplants were included in the outcome because we assumed that these patients would have died without transplant.

Non-urgent transplants were not considered in the primary end point analysis.

We considered a death sudden if it occurred within 1 hour of the onset of unexpected symptoms or during sleep in patients who were symptomatically stable during the 24 hours preceding death, or was unwitnessed death and occurred within 1 hour of the patient last being seen alive. Death from heart failure was considered to have occurred in conjunction with a worsening of congestive symptoms.

\section{Statistical analysis}

Comparisons between groups for continuous variables were performed by the ANOVA or MannWhitney test when appropriate. Categorical variables were compared by the Chi-square test. The association between prognostic variables and the outcome (cardiac death or urgent heart transplantation) was analysed by univariate and multivariate logistic regression. For each significant prognostic variable, the corresponding odds ratio (OR) and 95\% confidence interval (CI) were computed. In building multivariate models, two different sets of candidate variables were considered. The first set included only non-invasively measured parameters, while the second set included both non-invasively and invasively measured parameters. Accordingly, the two models have been referred to as respectively non-invasive and invasive model.

To assess the overall predictive discrimination of each logistic model, we computed the area under the receiver operator characteristic (ROC) curve ob- 
tained from the model. ${ }^{8}$ This area measures the ability of the model to separate patients with poor outcome from those who did not have a poor outcome. A ROC curve area of 0.5 indicates no discrimination power, whereas an area of 1 indicates perfect discrimination. Selection of variables to be included in the multivariate models was performed using the stepwise method. In all hypothesis tests a $\mathrm{p}$ value $<0.05$ was considered statistically significant.

\section{Results}

\section{Patients' characteristics}

The clinical characteristics of the 980 patients enrolled in the study are shown in table 1 . The mean age of the patients was $53 \pm 9$ years (range 15 to 77 years) and $85 \%$ of them were male. The etiology of heart failure was coronary artery disease in $44 \%$ (428 patients), a primary dilated cardiomyopathy in $39 \%$ (384 patients), and other cardiac disease (hypertension, valvular disease) in 17\% (168 patients). Forty-six percent were categorized as having NYHA functional class III-IV disease and the remaining 54\% were in NYHA class I-II. The mean echocardiographic left ventricular ejection fraction was $25 \pm 8 \%$. Thus the patients presented a compromised hemodynamic profile and decreased exercise capacity.

\section{Relationship between anemia and clinical findings}

Of the total study population, $19 \%$ of patients were anemic. Anemia was more frequent in females and in older patients. No differences were found between patients with and without anemia in LVEF, LVEDD, LVESD, deceleration time, cardiac index, history of hypertension, family predisposition, smoking habits, serum sodium and potassium concentrations, and etiology of CHF. However, anemic patients had a lower body mass index ( $24 \pm 3$ vs. $25 \pm 4$ $\mathrm{Kg} / \mathrm{m}^{2} \mathrm{p}<0.001$ ), a worse functional class (NYHA functional class III-IV $64 \%$ vs $41 \% \mathrm{p}<0.001$ ), poorer exercise capacity (12.4 vs. $14.8 \mathrm{ml} / \mathrm{kg} / \mathrm{min}$ peak $\left.\mathrm{VO}_{2}, \mathrm{p}<0.001\right)$ and higher right $(7 \pm 5 \mathrm{vs} 5 \pm 4 \mathrm{mmHg}$, $\mathrm{p}<0.001)$ and left ventricular filling $(21 \pm 9$ vs. $19 \pm 10$ $\mathrm{p}<0.001$ ) pressures (table 1 ).

\section{Outcome events}

Over a three-year follow-up there were 288 (29\%) outcome events. Cardiac death occurred in 236 (24\%) patients; progressive CHF accounted for $141(60 \%)$ of these deaths, while $95(40 \%)$ were sudden. Fifty-two $(5 \%)$ patients received a heart transplant in Status I. The percentage of patients who therefore had suffered a hard cardiac event was higher among anemic than among non-anemic patients $(39 \%$ vs. $27 \% \mathrm{p}<001)$ (figure 1).

Table 1. - Baseline clinical, Doppler echocardiographic and hemodynamic characteristics in all patients and in the patients with and without anemia

\begin{tabular}{|c|c|c|c|c|}
\hline & All & Anemic & Non-anemic & p \\
\hline $\mathbf{N}$ & 980 & 187 & 793 & \\
\hline Age (years) & $53 \pm 9$ & $55 \pm 9$ & $52 \pm 9$ & $<0.001$ \\
\hline Sex (Male/Female) & $834 / 146$ & $134 / 53$ & 700/93 & $<0.001$ \\
\hline Etiology (ischemic/idiopathic/other) & $428 / 384 / 168$ & $81 / 59 / 47$ & $347 / 325 / 121$ & $<0.001$ \\
\hline NYHA I-II/III-IV & $533 / 447$ & $67 / 120$ & $466 / 327$ & $<0.001$ \\
\hline Heart rate (beats/min) & $80 \pm 18$ & $81 \pm 18$ & $80 \pm 18$ & Ns \\
\hline Systolic pressure $(\mathrm{mmHg})$ & $112 \pm 16$ & $108 \pm 15$ & $111 \pm 16$ & 0.004 \\
\hline Peak $\mathrm{VO}_{2}(\mathrm{ml} / \mathrm{min} / \mathrm{Kg})$ & $14.4 \pm 4$ & $12.4 \pm 3$ & $14.8 \pm 5$ & $<0.001$ \\
\hline LVEDD $(m m)$ & $71 \pm 10$ & $71 \pm 11$ & $71 \pm 10$ & Ns \\
\hline LVESD $(\mathrm{mm})$ & $60 \pm 11$ & $60 \pm 12$ & $60 \pm 11$ & Ns \\
\hline LVEF (\%) & $25 \pm 8$ & $25 \pm 8$ & $25 \pm 8$ & Ns \\
\hline $\mathbf{E} / \mathbf{A}$ & $2.1 \pm 1.5$ & $2.3 \pm 1.6$ & $2.1 \pm 1.5$ & Ns \\
\hline Deceleration time $\mathbf{E}$ ( $\mathrm{msec}$ ) & $138 \pm 54$ & $138 \pm 48$ & $139 \pm 55$ & Ns \\
\hline Mitral regurgitation grade 2-3 $(N(\%))$ & 379(39) & $82(44)$ & $297(37)$ & Ns \\
\hline Cardiac index $\left(\mathrm{l} / \mathrm{min} / \mathrm{m}^{2}\right)$ & $2.1 \pm 0.5$ & $2.1 \pm 0.5$ & $2.1 \pm 0.6$ & Ns \\
\hline Pulmonary wedge pressure $(\mathrm{mmHg})$ & $19 \pm 6$ & $21 \pm 9$ & $19 \pm 10$ & 0.007 \\
\hline Right atrial pressure $(\mathrm{mmHg})$ & $6 \pm 5$ & $7 \pm 5$ & $5 \pm 4$ & $<0.001$ \\
\hline $\mathbf{B M I}\left(K g / m^{2}\right)$ & $25 \pm 4$ & $24 \pm 3$ & $25 \pm 4$ & $<0.001$ \\
\hline \multicolumn{5}{|l|}{ THERAPY } \\
\hline Diuretics $(N(\%))$ & $921(94)$ & $183(98)$ & $738(93)$ & 0.01 \\
\hline Digitalis $(N(\%))$ & $578(59)$ & $142(76)$ & $436(55)$ & $<.0001$ \\
\hline ACE-inhibitors $(N(\%))$ & $829(85)$ & $146(78)$ & $683(86)$ & 0.01 \\
\hline Beta-blockers $(N(\%))$ & $155(16)$ & $29(15)$ & $126(16)$ & Ns \\
\hline
\end{tabular}

Legend: BMI: body mass index; E/A: early to late diastolic peak velocity ratio; LVEDD: left ventricular end-diastolic diameter; LVESD: left ventricular end-systolic diameter; LVEF: left ventricle ejection fraction; NYHA: New York Heart Association class. Continuous variables are described as mean \pm SD. 


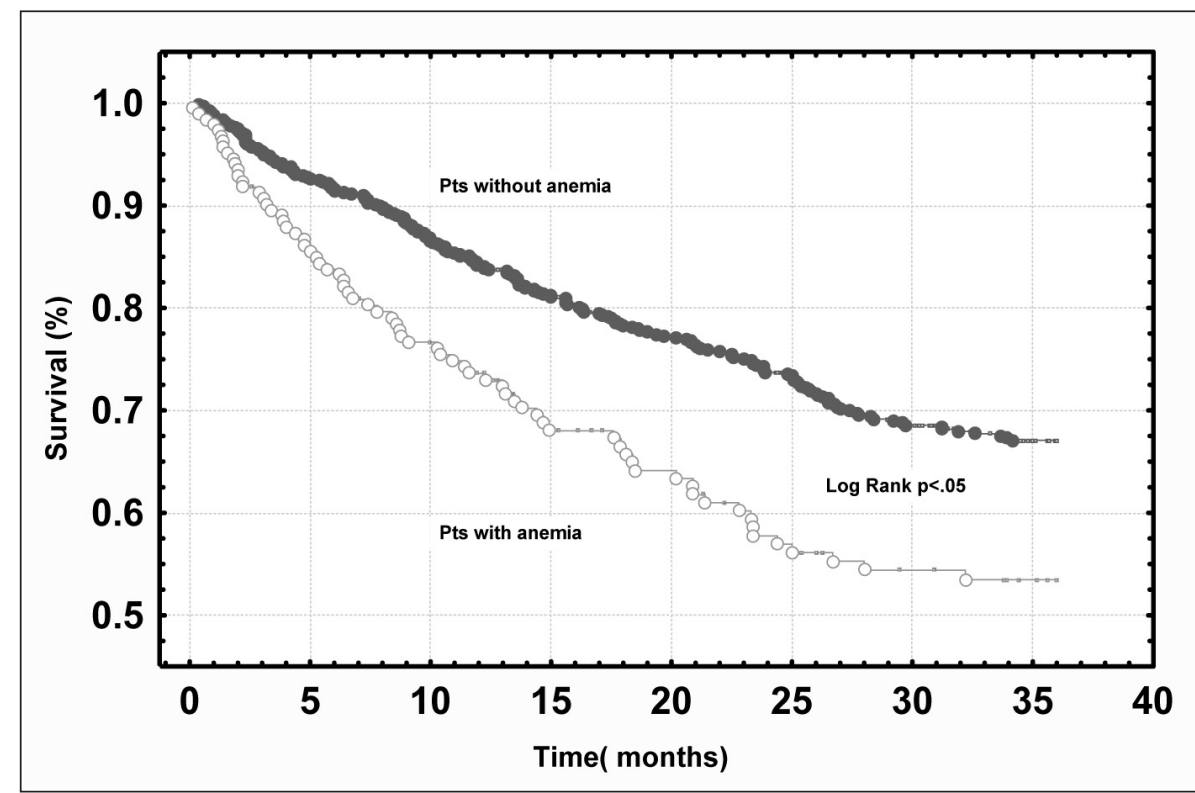

Figure 1. - Survival curves among heart failure patients with and without anemia.

and in those without renal failure $(\mathrm{p}=0.03)$.

\section{Multivariate logistic analysis}

Among all clinical and Biochemical and hematologic non-invasively measured parameters which significantly predicted primary outcome in the univariate analyses, the following set of variables in the multivariate predictive model were predictive (table 4): NYHA functional class, mitral regurgitation, anemia, LVEF and serum sodium. When we repeated the multivariate analysis including all noninvasive parameters and peak $\mathrm{VO}_{2}$, the final model predicting the primary out-

\section{Univariate analysis}

Univariate logistic regression analysis identified many variables that were predictive of cardiac mortality or urgent cardiac transplantation in the threeyear follow-up (table 2).

We also analyzed the relation between chronic renal failure $(\mathrm{CRF})$ and anemia and found that anemia was more frequent in patients with CRF than in patients with normal renal function ( $38 \%$ vs. $18 \%$; $=0.001)$, anemia, however, maintained its univariate prognostic value both in CRF patients $(\mathrm{p}=0.015)$ come included: NYHA functional class, mitral regurgitation, LVEF, serum sodium and peak $\mathrm{VO}_{2}$, but not anemia. In the multivariate model incorporating non-invasive and invasive parameters, the following variables were independent predictors (table 3): NYHA functional class, mitral regurgitation, LVEF, serum sodium and right atrial pressure. To appraise differences in prognostic accuracy between the various prognostic models (with peak $\mathrm{VO}_{2}$ or anemia, or RAP), we compared them using ROC curves. The areas under the ROC curves of the three models were not significantly different (figure 2, table 3 ).

Table 2. - Univariate analysis: Univariate predictors of cardiac death or urgent cardiac transplantation

\begin{tabular}{|c|c|c|c|}
\hline & $O R$ & $C I$ & $p$ \\
\hline Sex & 0.85 & $0.57-1.27$ & Ns \\
\hline Age & 1.00 & $0.99-1.02$ & Ns \\
\hline Etiology & 0.99 & $0.82-1.20$ & Ns \\
\hline NYHA & 2.54 & $1.92-3.38$ & $<0.001$ \\
\hline Heart rate & 1.02 & 1.00-1.03 & 0.007 \\
\hline Systolic pressure & 0.96 & $0.95-0.97$ & $<0.001$ \\
\hline Peak $\mathrm{VO}_{2}$ & 0.89 & $0.86-0.93$ & $<0.001$ \\
\hline LVEDD & 1.02 & 1.01-1.04 & 0.002 \\
\hline LVESD & 1.03 & 1.02-1.04 & 0.001 \\
\hline LVEF & 0.93 & $0.91-0.95$ & $<0.001$ \\
\hline Mitral regurgitation & 1.94 & $1.47-2.57$ & $<0.001$ \\
\hline Cardiac index & 0.48 & $0.36-0.64$ & $<0.001$ \\
\hline Pulmonary wedge pressure & 1.05 & 1.03-1.06 & $<0.001$ \\
\hline Right atrial pressure & 1.12 & 1.08-1.15 & $<0.001$ \\
\hline Anemia & 1.67 & $1.20-2.33$ & 0.002 \\
\hline BUN & 1.01 & 1.01-1.02 & 0.001 \\
\hline Creatinine & 1.66 & $1.19-2.33$ & 0.003 \\
\hline Serum Sodium & 0.86 & 0.82-0.89 & $<0.001$ \\
\hline Bilirubin & 1.67 & $1.36-2.04$ & $<0.001$ \\
\hline
\end{tabular}

Legend: BUN: blood urea nitrogen. OR: Odds ratio: CI:95\% confidence interval 
Table 3. - Multivariate logistic regression models with non-invasively and invasively measured variables

\begin{tabular}{|c|c|c|c|c|}
\hline \multicolumn{5}{|c|}{ Multivariate non-invasive } \\
\hline & Wald $\chi^{2}$ & $\mathbf{p}$ & OR(CI) & AUC \\
\hline Serum sodium & 37.55 & $<.0001$ & $0.88(0.84-0.91)$ & \\
\hline LVEF & 19.13 & $<.0001$ & $0.95(0.93-0.97)$ & \\
\hline NYHA Class III-IV vs. NYHA Class I-II & 14.16 & 0.0002 & $1.79(1.32-2.44)$ & 0.720 \\
\hline Mitral regurgitation $2-3$ vs. $0-1$ & 8.32 & 0.0039 & $1.55(1.15-2.09)$ & \\
\hline Anemia & 3.91 & 0.04 & $1.44(1.00-2.06)$ & \\
\hline \multicolumn{5}{|c|}{ Multivariate non-invasive model including peak $\mathrm{VO}_{2}$} \\
\hline Serum sodium & 30.4487 & $<.0001$ & $0.88(0.84-0.92)$ & \\
\hline LVEF & 12.759 & 0.0004 & $0.95(0.93-0.98)$ & \\
\hline NYHA class III-IV vs. I-II & 8.729 & 0.0031 & $1.64(1.18-2.82)$ & 0.719 \\
\hline $\mathrm{VO}_{2}$ peak & 7.862 & 0.005 & $0.94(0.90-0.98)$ & \\
\hline Mitral regurgitation $2-3$ vs. $0-1$ & 6.519 & 0.0107 & $1.51(1.10-2.08)$ & \\
\hline \multicolumn{5}{|c|}{ Multivariate invasive model } \\
\hline RAP & 22.098 & $<.0001$ & $1.086(1.04-1.12$ & \\
\hline Serum sodium & 20.665 & $<.0001$ & $0.90(0.86-0.94)$ & \\
\hline LVEF & 15.629 & $<.0001$ & $0.95(0.93-0.97)$ & 0.719 \\
\hline Mitral regurgitation 2-3 vs. 0-1 & 5.891 & 0.0152 & $1.48(1.08-2.05)$ & \\
\hline NYHA class III-IV vs. I-II & 5.481 & 0.019 & $1.49(1.06-2.07)$ & \\
\hline
\end{tabular}

Legend: AUC: area under the receiver operator characteristic (ROC) curve.

Table 4. - Laboratory findings characteristics in all patients and in the patients with and without anemia

\begin{tabular}{lcccc}
\hline & All & Anemic & Non-anemic & p \\
\hline Hemoglobin $(\mathrm{g} / \mathrm{dl})$ & $13.5 \pm 1.8$ & $10.8 \pm 1.1$ & $14.2 \pm 1.3$ & $<0.001$ \\
Red cell count $\left(\mathrm{x} 10^{12} / \mathrm{l}\right)$ & $4.6 \pm .6$ & $4.0 \pm .6$ & $4.7 \pm .5$ & $<0.001$ \\
White cell count $\left(\mathrm{x} 10^{9} / \mathrm{l}\right)$ & $7.3 \pm 1.9$ & $7.0 \pm 2.0$ & $7.3 \pm 1.9$ & Ns \\
Platelet count $\left(\mathrm{x} 10^{9} / \mathrm{l}\right)$ & $222 \pm 71$ & $233 \pm 84$ & $219 \pm 67$ & Ns \\
Potassium $(\mathrm{meq} / \mathrm{l})$ & $4.3 \pm \mathbf{0 . 4}$ & $4.3 \pm 0.4$ & $4.3 \pm .4$ & Ns \\
BUN $(\mathrm{mg} / \mathrm{dl})$ & $55 \pm 26$ & $64 \pm 32$ & $53 \pm 23$ & $<0.001$ \\
Creatinine(mg/dl) & $1.24 \pm 0.45$ & $1.33 \pm 0.45$ & $1.22 \pm 0.45$ & $<0.001$ \\
Serum sodium $(\mathrm{meq} / \mathrm{l})$ & $139 \pm 4$ & $138 \pm 4$ & $139 \pm 4$ & $<0.03$ \\
Albumin $(\mathrm{g} / \mathrm{dl})$ & $4.37 \pm .83$ & $4.1 \pm .51$ & $4.6 \pm .50$ & $<0.001$ \\
Cholinesterases & $8730 \pm 2762$ & $7489 \pm 2671$ & $9033 \pm 2701$ & 0.003 \\
Cholesterol $(\mathrm{mg} / \mathrm{dl})$ & $197 \pm 49$ & $179 \pm 54$ & $202 \pm 46$ & $<0.001$ \\
Bilirubin $(\mathrm{mg} / \mathrm{dl})$ & $1.15 \pm 0.67$ & $1.17 \pm .65$ & $1.17 \pm .67$ & Ns \\
\hline
\end{tabular}

Legend: BUN: blood urea nitrogen.

\section{Discussion}

The present study, conducted in a large cohort of patients with CHF of different etiologies and with various degrees of cardiac dysfunction, demonstrates that anemia is associated with prognosis in CHF. Our study confirms and extends previous evidence. $3-5,9-20$ In agreement with previous studies, anemia was associated with a worse NYHA functional class, exercise capacity and hemodynamic profile (table 5). However this study is the first that analyzed the independent prognostic power of anemia among other considered non-invasive and invasive prognostic indices which are validated in routine clinical practice. In agreement with previous studies it identifies the relationship between anemia and a "hard" cardiac event but highlights the fact that the use of complex non-invasive and invasive prognostic models obtained in different settings provides similar prognostic power to that with the simpler measurement of anemia.

This result can be explained by the close physiopathologic relationship that exists between anemia and the different prognostic determinants. ${ }^{21}$

\section{Anemia in chronic heart failure}

Several different factors may work together in $\mathrm{CHF}$ to cause anemia. Impaired renal function and 


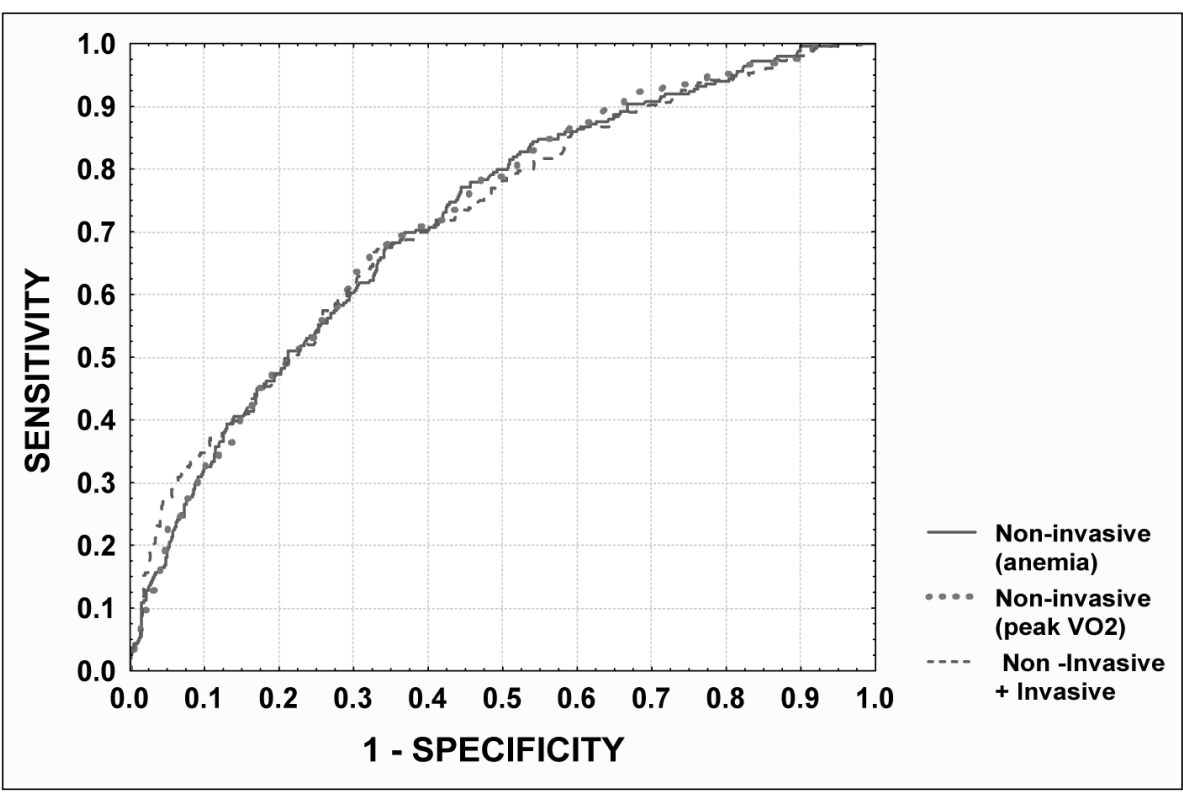

Figure 2. - ROC curves for the combined end-point of cardiac mortality or urgent heart transplantation using non-invasive and invasive models.

disturbance of erythropoietin metabolism can be associated with anemia; on the other hand, lower $\mathrm{Hb}$ can be associated with higher creatinine. Recent data show how the use of erythropoietin can modify prognosis in CHF patients. ${ }^{4}$ We analyzed our patients in two groups according to whether they did or did not have renal failure and found that the association between low $\mathrm{Hb}$ and increased cardiac mortality was present in both subsets of patients; likewise, in the SOLVD study, anemia was related to an increased risk of mortality after adjustment for renal dysfunction. ${ }^{11}$ These apparent discrepancies can be explained by the different etiologies of the anemia in the various CHF populations evaluated.

Anemia in CHF is at least partially due to excessive production of cytokines (such as tumor necrosis factor alpha (TNF $\alpha)$ ) and leukotrienes that interfere both with the effect of erythropoietin on bone marrow (they inhibit its effect) and the release of stored iron in the reticuloendothelial system. ${ }^{22}$ Recent data show that TNF $\alpha$ may suppress both early and late stages of hematopoiesis and can induce programmed cell death with consequent decrease of hematopoiesis. 23

Only the red cell count was decreased in our anemic patients; platelets and white cell counts were similar to those in the non-anemic patients (table 4). This observation allows us to draw two important implication: first, TNF could play an important role in the genesis of anemia in these patients; second, the anemia cannot be considered simply as the result of hemodilution, or of general illness, because otherwise all the cell lineages would be affected.

Cardiac cachexia due to malnutrition, a catabolic state, malabsorption, and atrophic gastritis can induce anemia in CHF. 24 We analyzed the nutritional state of our population and found that the BMI was lower in anemic patients than in non-anemic ones. Compromised liver function is often associated with chronic heart failure. A conjunction of different causes (hypoxia, chronic congestion, malnutrition) can decrease the biosynthetic capacity of the liver with decreased synthesis of glycine and succinyl-CoA. These alterations could limit the synthesis of the heme group precursor of $\Delta$ aminolevulinate acid and, finally, of hemoglobin. 25,26 In this scenario the final result is the development of mild normocytic anemia. In our cohort of patients, the anemic ones had poorer liver synthesis function (table 4).

Different studies underline the role of anemia in modifying the natural outcome of CHF.27-31 In this context its prospective prognostic informative content is transferred to already consolidated markers (i.e. NYHA class, mitral regurgitation, volemia, peak $\mathrm{VO}_{2}$ ). Thus anemia should also be considered as one of chronic conditions that determine a poor prognosis.

\section{Prognostic models}

Various sets of prognostic variables for patients with CHF have been proposed in the literature. In a scenario in which it is essential to consider scarce resources, 32 it is important to identify simpler prognostic models that are practical in different settings. In primary care, a simple model containing anemia and other established non-invasive markers can stratify risk and identify patients who should be referred to specialist intensive care. In this simple model the parameters of peak $\mathrm{VO}_{2}$ and anemia compete. Peak $\mathrm{VO}_{2}$ showed a greater prognostic power because it combines both oxygen transport capacity (i.e. hemoglobin) but also it's central and peripheral determinants. The multivariate model selects this variable instead of anemia. But cardiopulmonary exercise test $\left(\mathrm{VO}_{2}\right)$ are rarely performed in the context of community care and their prognostic power is weakened by the wide range of values. ${ }^{33}$ In contrast when anemia is considered in the model, prognostic accuracy remains substantially unchanged. Analogous considerations could also be made for invasive variables.

\section{Open clinical questions}

Although our results once again underline the strong link between anemia, CHF and mortality, there are many unclear areas in this relationship that deserve further investigation. Currently there are no data about the type of anemia in patients with chronic heart failure. Silverberg analyzed the correlation between chronic diseases (such as chronic renal failure, chronic heart failure, chronic inflammatory bowel disease and rheumatoid arthritis) and anemia. ${ }^{4}$ Differences between anemia Classifica- 


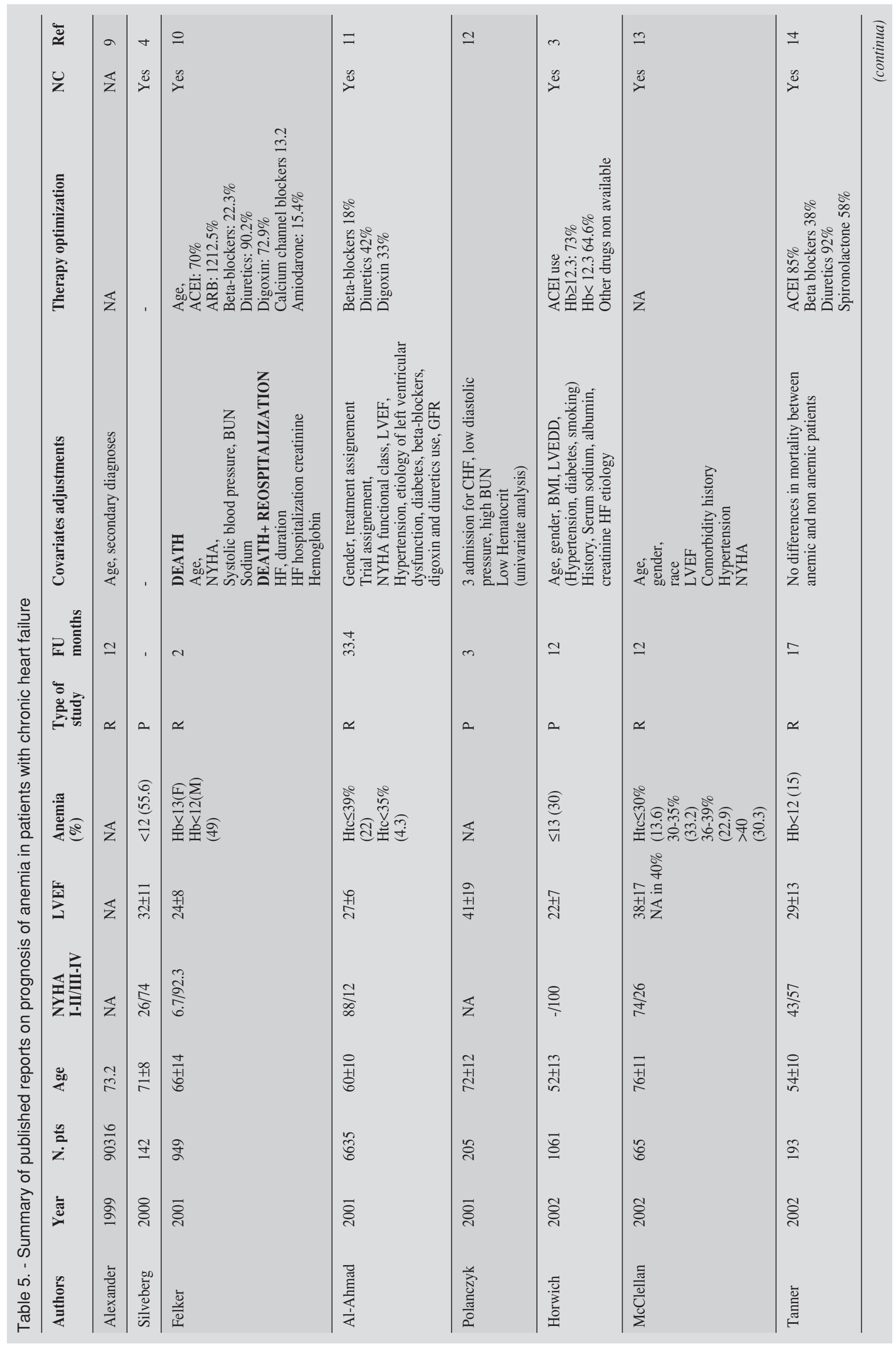




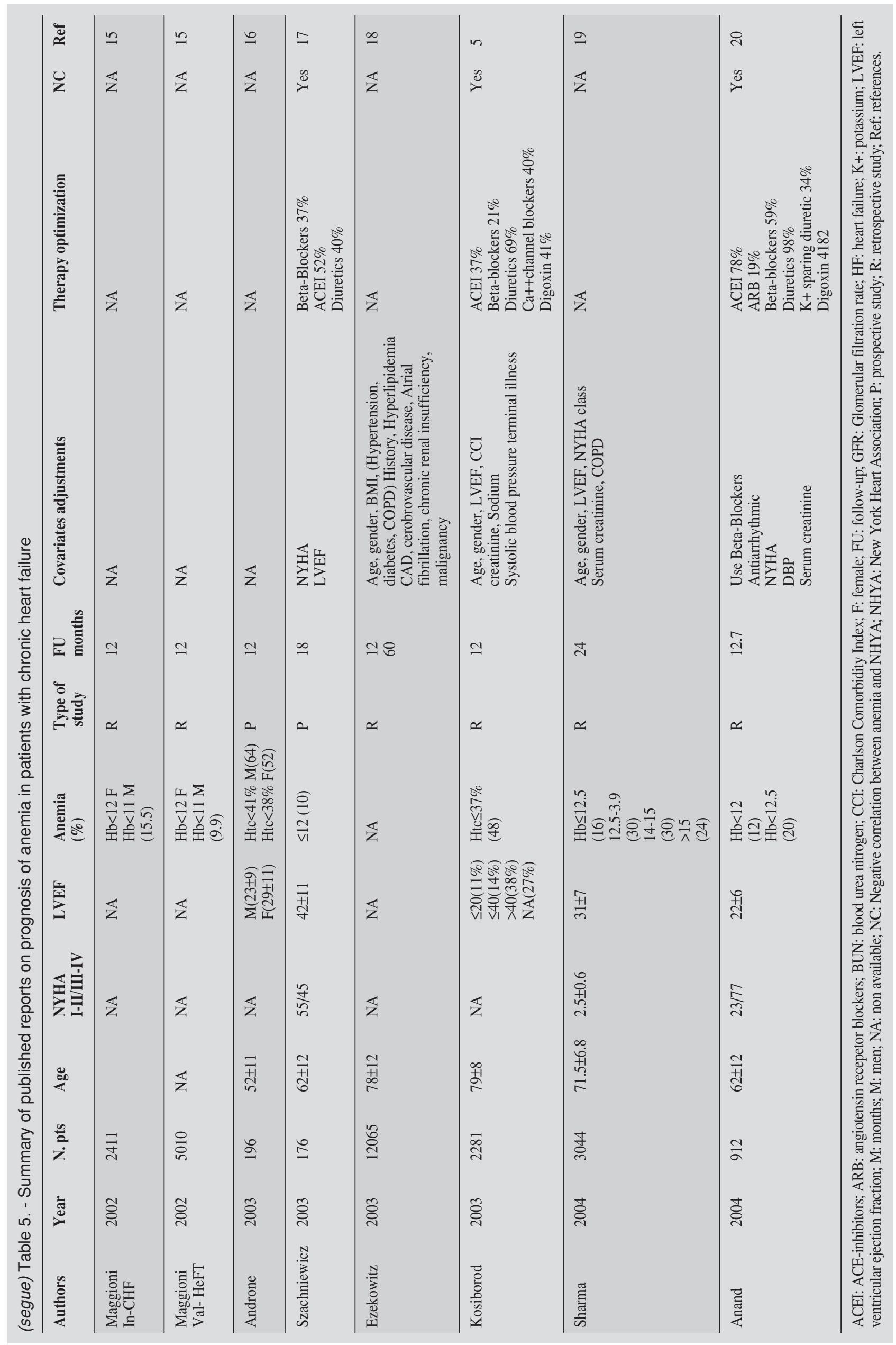


tion, population characteristics, study design, therapeutic optimization limits the comparison between several studies. The prognostic power of anemia in many reports was not adjusted for all established non-invasive and invasive prognostic variables (table 5). Gender and diastolic heart failure have not been evaluated in the different studies. Silverberg showed favorable clinical results after the use of erythropoietin and iron, but in a randomized clinical trial in anemic patients with end-stage renal and heart failure, normalization of hematocrit produced by erythropoietin and iron infusion was associated with increased myocardial infarction. 34 Currently there are few data about the relationship between hemoglobin changes and long term prognosis in CHF patients. ${ }^{20}$

\section{Study limitations}

This study has limitations. First, we examined selected patients who were entering a heart transplantation program. Second, elderly patients, those with diastolic heart failure, and women were underrepresented. Third, the etiology of the anemia was not studied. Finally, several iatrogenic causes of anemia and possible therapeutic treatments undertaken, which could have conditioned the clinical outcome, were not considered.

\section{Conclusions}

The present study was conducted in a large cohort of patients with CHF of different etiology and degree of cardiac dysfunction. The study demonstrates that anemia was associated with a worse NYHA functional class, exercise capacity and hemodynamic profile. We found that the relationship between anemia and mortality is independent of noninvasive established prognostic factors. In a selected prognostic model using simple non-invasive predictors which include anemia, the addition of complex independent predictors did not increase the accuracy of the model in predicting cardiac mortality. Supplementary studies are needed to understand the etiology and pathology of anemia in CHF patients in order to verify whether treatment of anemia will indeed improve survival.

Acknowledgments: We are grateful to Prof. P. Sleight for kindly reviewing the manuscript. We thank Dr. R. Latini and Dr. A.P. Maggioni for their analytic and constructive criticisms.

\section{LIST OF ABBREVIATIONS}

CHF: chronic heart failure

$\mathrm{Hb}$ : hemoglobin

LVEF: Left ventricular ejection fraction

Pts: patients

$\mathrm{AUC}_{\mathrm{ROC}}$ : Area Under Curve Receiver Operator Curve

ROC: Receiver Operator Curve

\section{References}

1. Stewart S, MacIntyre K, MacLeod MMC, Bailey AEM, Capewell S, MacMurray JJV. Trends in hospitalization for heart failure in Scotland 1990-1996- An epidemic that has reached its peak? Eur Heart J 2001; 22: 209-17.

2. Cowburn PJ, Cleland JGF, Coats AJS, Komajda M. Risk stratification in chronic heart failure. Eur Heart J 1998; 19: 696-710.

3. Horwich TB, Fonarow GC, Hamilton MA, MacLellan WR, Borenstein J. Anemia is associated with worse symptoms, greater impairment in functional capacity and a significant increase in mortality in patients with advanced heart failure. J Am Coll Cardiol 2002 Jun 5; 39: 1780-6.

4. Silverberg DS, Wexler D, Blum M, Tchebiner J, Sheps D, Keren G, Schwartz D, Baruch R, Yachnin T, Shaked M, Zubkov A, Steinbruch S, Iaina A. The correction of anemia in severe resistant heart failure with erythropoietin and intravenous iron prevents the progression of both the heart and the renal failure and markedly reduces hospitalization. Clin Nephrol 2002 Jul; 58 Suppl 1: S37-45.

5. Kosiborod M, Smith GL, Radford MJ, Foody JM, Krumholz HM. The prognostic importance of anemia in patients with heart failure. Am J Med 2003 Feb 1; 114 (2): 112-9.

6. Gordon EP, Schnittger I, Fitzgerald PJ, Williams P, Popp R. Reproducibility of left ventricular volumes by two-dimensional echocardiography. J Am Coll Cardiol 1983; 2: 506-13.

7. Helmcke F, Nanda NC, Hsiung MC, Soto B, Adey CK, Goyal RG, Gatewood RP Jr. Color Doppler assessment of mitral regurgitation with orthogonal planes. Circulation 1987; 75 (1): 175-83.

8. Hanley JA, McNeil BJ. A method of comparing the areas under receiver operating characteristic curves derived from the same cases. Radiology 1983; 148: 839-43.

9. Alexander M, Grumbach K, Remy L, Rowell R, Massie $\mathrm{BM}$. Congestive heart failure hospitalizations and survival in California: patterns according to race/ethnicity. Am Heart J 1999 May; 137 (5): 919-27.

10. Felker GM, Gattis WA, Leimberger JD, Adams KF, Cuffe MS, Gheorghiade M, O'Connor CM. Usefulness of anemia as a predictor of death and rehospitalization in patients with decompensated heart failure. Am J Cardiol 2003 Sep 1; 92 (5): 625-8.

11. Al-Ahmad A, Rand WM, Manjunath G, Konstam MA, Salem DN, Levey AS, Sarnak MJ. Reduced kidney function and anemia as risk factors for mortality in patients with left ventricular dysfunction. J Am Coll Cardiol 2001 Oct; 38 (4): 955-62.

12. Polanczyk CA, Newton C, Dec GW, Di Salvo TG. Quality of care and hospital readmission in congestive heart failure: an explicit review process. J Card Fail 2001 Dec; 7 (4): 289-98.

13. McClellan WM, Flanders WD, Langston RD, Jurkovitz C, Presley R. Anemia and renal insufficiency are independent risk factors for death among patients with congestive heart failure admitted to community hospitals: a population-based study. J Am Soc Nephrol 2002 Jul; 13 (7): 1928-36.

14. Tanner H, Moschovitis G, Kuster GM, Hullin R, Pfiiffner D, Hess OM, Mohacsi P. The prevalence of anemia in chronic heart failure. Int J Cardiol 2002 Nov; 86 (1): 115-21.

15. Maggioni A, Latini R, Anand I, Barlera S, Gonzini L, Opasich C, Tavazzi L, Cohn JN. Prevalence and prognostic role of anemia in patients wuth heart failure in the INCHF and the Val-HeFT trial. Eur Heart Journal 2002; 4 (suppl) (abs 1480).

16. Androne AS, Katz SD, Lund L, LaManca J, Hudaihed A, Hryniewicz K, Mancini DM. Hemodilution is common in 
patients with advanced heart failure. Circulation 2003 Jan 21; 107 (2): 226-9.

17. Szachniewicz J, Petruk-Kowalczyk J, Majda J, Kaczmarek A, Reczuch K, Kalra PR, Piepoli MF, Anker SD, Banasiak W, Ponikowski P. Anemia is an independent predictor of poor outcome in patients with chronic heart failure. Int J Cardiol 2003 Aug; 90 (2-3): 303-8.

18. Ezekowitz JA, McAlister FA, Armstrong PW. Anemia is common in heart failure and is associated with poor outcomes: insights from a cohort of 12065 patients with new-onset heart failure. Circulation 2003 Jan 21; 107 (2): 223-5.

19. Sharma R, Francis DP, Pitt B, Poole-Wilson PA, Coats AJ, Anker SD. Haemoglobin predicts survival in patients with chronic heart failure: a substudy of the ELITE II trial. Eur Heart J 2004 Jun; 25 (12): 1021-8.

20. Anand I, McMurray JJ, Whitmore J, Warren M, Pham A, McCamish MA, Burton PB. Anemia and its relationship to clinical outcome in heart failure. Circulation 2004 Jul 13; 110 (2): 149-54. Epub 2004 Jun 21.

21. Harnett JD, Kent GM, Foley RN, Parfrey PS. Cardiac function and hematocrit level. Am J Kidney Dis 1995 Apr; 25 (4 Suppl 1): S3-7.

22. Demeter J, Messer G, Schrezenmeier H. Clinical relevance of the TNF-alpha promoter/enhancer polymorphism in patients with aplastic anemia. Ann Hematol 2002 Oct; 81 (10): 566-9.

23. Selleri C, Sato T, Anderson S, Young NS, Maciejewski JP. Interferon-gamma and tumor necrosis factor-alpha suppress both early and late stages of hematopoiesis and induce programmed cell death. J Cell Physiol 1995 Dec; 165 (3): 538-46.

24. Anker SD, Sharma R. The syndrome of cardiac cachexia. Int J Cardiol 2002 Sep; 85 (1): 51-66.

25. Furuyama K, Sassa S. Interaction between succinyl CoA synthetase and the heme-biosynthetic enzyme ALAS-E is disrupted in sideroblastic anemia. J Clin Invest 2000 Mar; 105 (6): 757-6.

26. Ferreira GC, Gong J. 5-Aminolevulinate synthase and the first step of heme biosynthesis. J Bioenerg Biomembr 1995 Apr; 27 (2): 151-9. Review.

27. Schafer GE, Rehbein C, Stiegler T, Hampl H. Renal anemia and its hemodynamic response-findings invasively determined over a period of 20 years. Clin Nephrol 2002 Jul; 58 Suppl 1: S52-7.

28. Schrier RW, Fassett RG. Pathogenesis of sodium and water retention in cardiac failure. Ren Fail 1998 Nov; 20 (6): 773-81. Review.

29. McMahon LP, McKenna MJ, Sangkabutra T, Mason K, Sostaric S, Skinner SL, Burge C, Murphy B, Crankshaw D. Physical performance and associated electrolyte changes after haemoglobin normalization: a comparative study in haemodialysis patients. Nephrol Dial Transplant 1999 May; 14 (5): 1182-7.

30. Opasich C, Febo O, Riccardi PG, Traversi E, Forni G, Pinna G, Pozzoli M, Riccardi R, Mortara A, Sanarico M, Cobelli F, Tavazzi L. Concomitant factors of decompensation in chronic heart failure. Am J Cardiol 1996 Aug 1; 78 (3): 354-7.

31. Anand IS, Chandrashekhar Y, Ferrari R, Poole-Wilson PA, Harris PC. Pathogenesis of oedema in chronic severe anaemia: studies of body water and sodium, renal function, haemodynamic variables, and plasma hormones. $\mathrm{Br}$ Heart J 1993 Oct; 70 (4): 357-62.

32. Steinwachs DM, Collins-Nakai RL, Cohn L, Garson A, Wolk MJ The future of cardiology: utilization and costs of care. J Am Coll Cardiol 2000; 35 (Suppl B): 91B-98B.

33. Opasich C, Pinna GD, Bobbio M, Sisti M, Demichelis B, Febo O, Forni G, Riccardi R, Riccardi PG, Capomolla S, Cobelli F, Tavazzi L. Peak exercise oxygen consumption in chronic heart failure: toward efficient use in the individual patient. J Am Coll Cardiol 1998 Mar 15; 31 (4): 766-75.

34. Besarab A, Bolton WK, Browne JK, Egrie JC, Nissenson AR, Okamoto DM, Schwab SJ, Goodkin DA. The effects of normal as compared with low hematocrit values in patients with cardiac disease who are receiving hemodialysis and epoetin. N Engl J Med 1998 Aug 27; 339 (9): 584-90.

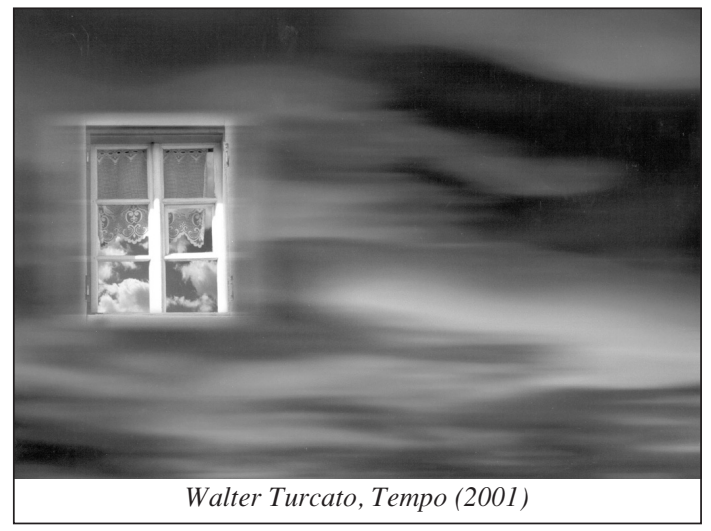

